FIU Law Review

Fall 2012

\title{
Not Just the NFL: Compensation, Litigation, and Public Health in Concussion Cases
}

John G. Culhane

Widener University School of Law

Follow this and additional works at: https://ecollections.law.fiu.edu/lawreview

Part of the Other Law Commons

Online ISSN: 2643-7759

\section{Recommended Citation}

John G. Culhane, Not Just the NFL: Compensation, Litigation, and Public Health in Concussion Cases, 8 FIU L. Rev. 5 (2012).

DOI: https://dx.doi.org/10.25148/lawrev.8.1.5

This Article is brought to you for free and open access by eCollections. It has been accepted for inclusion in FIU Law Review by an authorized editor of eCollections. For more information, please contact lisdavis@fiu.edu. 


\title{
Not Just the NFL: Compensation, Litigation, and Public Health in Concussion Cases
}

\author{
John G. Culhane
}

\section{INTRODUCTION}

Should football be abolished?

That question is just now beginning to be asked. The New York Times recently reported on a controversy that a retired New Hampshire doctor, one Paul Butler, had stirred up when he recommended shutting down the high school football program in Dover, New Hampshire because of the serious risk of concussion the sport poses. ${ }^{1}$ Butler, himself a former player (and currently a member of the local school board), had become convinced that cutting off the school's involvement in the sport was both a moral and legal necessity. ${ }^{2}$ But in making a recommendation that one might have expected to go unnoticed, Butler inserted himself into a controversy that has taken on a complex role in the larger question over the proper role of sports-especially football.

Football, after all, is deeply embedded in the American experience, from the National Football League ("NFL")'s hold on television viewership all the way down to the Pee Wee level, where young boys learn the skills that may one day take them into high school, college, and perhaps even professional ball-and where, according to one recent story, some five young boys suffered concussions during a single, lop-sided game. ${ }^{4}$ Predictably, then, the calls to abolish tackle football have been most vocal regarding the younger levels, where the concern about the effect of concussions on developing brains seems likely to

\footnotetext{
Professor of Law and Director, Health Law Institute, Widener University School of Law; Lecturer, Yale University School of Public Health. Contributing writer to Slate Magazine; blog: http://wordinedgewise.org. Comments about this article should be directed to: jgculhane@widener.edu.

1 Paul Brownfield, A Town's Passion for Football, A Retired Doctor's Concern, N.Y.TIMES, Oct. 23, 2012, at B13, available at http:/www.nytimes.com/2012/10/24/sports/football/a-townspassion-for-football-a-retired-doctors-concern.html?pagewanted=all.

$I d$.

$I d$.

4 Ken Belson, A 5-Concussion Pee Wee Game Brings Penalties for the Adults, N.Y.TIMEs, Oct. 23, 2012, at A1, available at http://www.nytimes.com/2012/10/23/sports/football/pee-weefootball-game-with-concussions-brings-penalties-for-adults.html?pagewanted=all. Remarks by the coach of the winning team only served to exacerbate the concern: "This is football, not a Hallmark moment." Id.
} 
lead to a battle between public health experts and the coaches, parents, and fans for whom football is an important part of life.

To question the wisdom of continuing to play football is to take on players, fans, and (perhaps most significantly) the vast commercial enterprise that depends on the sport's enormous popularity. So it is hardly surprising that conservative commentators have assailed the pushback against the consequences of this violent sport. However inartfully, conservative football enthusiast Rush Limbaugh summed up a central strand of the position taken by many of the sport's defenders when he stated that the attack came from liberal "pantywaists" who want to take the risk out of life.

Whatever the political and cultural context of the debate, it is hardly surprising that people have begun to pose the ultimate question suggested by the current and entirely justified concern with concussions and other, more long-term consequences of the kind of repeated trauma that is a frequent consequence of participation. One of these consequences, chronic traumatic encephalopathy ("CTE"), has been linked to serious cognitive and physiological decline, disability, and death. ' From the legal perspective, too, the questions about the continued role and viability of football continue. The NFL is playing defense, on the receiving end of suits by more than 3,000 former players, whose complaints allege that the league failed to protect them, to provide for their health needs, and to inform them of the dangers they faced. ${ }^{8}$ A less high-profile suit was also filed by former college football players against the National Collegiate Athletic Association ("NCAA"), alleging that the NCAA similarly failed to inform them about the long-term risks of repeated head trauma.' Some of the details of particular cases should be enough to concern everyone. For

5 See Stefan Fatsis, Why Do We Let Kids Play Tackle Football?, SLATE (Nov. 14, 2012, 4:07 PM), http://www.slate.com/articles/sports/sports_nut/2012/11/pop_warner_football_kids_should_ not_be_allowed_to_put_on_helmets_and_knock.html. Fatsis provides a spirited discussion of the steps the Pop Warner league has taken to increase safety, and concludes, with some scientific justification, that no step short of banning tackle football will adequately address the problem. Id.

$6 \quad$ See Brownfield, supra note 1.

7 For a layperson's discussion of CTE, see Alan Schwarz, Suicide Reveals Signs of a Disease Seen in N.F.L., N.Y. TIMES, Sept. 13, 2010, at A1, available at http://www.nytimes.com/2010/09/14/sports/14football.html?_r=0.

8 See Lester Munson, Ex-players Open NFL Lawsuit Round, ESPN (July 16, 2012, $3: 32$ PM), http://espn.go.com/nfl/story/_id/8170900/player-suits-nfl-legal-strategies-take-form.

9 See George Vecsey, College Athletes Move Concussions into the Courtroom, N.Y. TIMES, Nov. 29, 2011, at B14, available at http://www.nytimes.com/2011/11/30/sports/ncaafootball/collegeplayers-move-concussions-issue-into-the-courtroom.html? pagewanted=all (including link to a copy of the class action complaint). 
example, in a recent op-ed piece, former Philadelphia Eagles and New England Patriots fullback Kevin Turner movingly described his struggle with amyotrophic lateral sclerosis ("ALS") and discussed NFL doctors sending him back into games after he had taken a hit to the head..$^{10}$ As he describes it, they would tell him that he "had merely had [his] 'bell rung." "11 His piece repeats the allegations of the complaint about how the NFL withheld information about the long-term effects of concussions, but in a chillingly personal way.

There are several reasons for this spike in interest about the risks of head trauma from football. Much of the credit goes to Alan Schwarz of the New York Times, who made the public aware of recent advances in research regarding the long-term consequences of repeated head trauma injuries as a result of playing football. ${ }^{13}$ Then, the NFL itself belatedly acknowledged these risks and has more recently donated \$30 million to the National Institutes of Health ("NIH") for research into brain injuries risked by athletes. ${ }^{14}$ Of course, this may be wise as one estimate of the total cost to the NFL from the lawsuits runs into the billions. ${ }^{15}$ The League has also begun to take steps to curb at least the most violent head-to-head impacts. ${ }^{16}$ Moving accounts of retired players suffering from dementia-most notably by Ben McGrath in the New Yorker-personalized the problem for many. ${ }^{17} \quad$ And several high-profile suicides, most recently by Junior Seau, have fueled the perception that impact-induced brain trauma can lead to the ultimate act of self-negation. ${ }^{18}$ This Symposium itself is

10 Kevin Turner, Saving Football From NFL, PHILA. INQUIRER, Nov. 16, 2012, at A22, available at http://articles.philly.com/2012-11-16/news/35157609_1_nfl-players-concussions-headimpacts.

11 Id.

12 See id.

13 Many of Mr. Schwarz's articles are collected at: Search, N.Y. TIMES, http://query.nytimes.com/search/sitesearch/\#/Alan+Schwarz+concussions (last visited Dec. 2, 2012).

14 See Mark Maske, NFL Donating \$30 Million to NIH for Brain Injury Research, WASH. Post, Sept. 5, 2012, at D02, available at http:/www.washingtonpost.com/blogs/footballinsider/wp/2012/09/05/nfl-donating-30-million-to-nih-for-brain-injury-research/.

15 See Munson, supra note 8. Munson cites an estimate of $\$ 1.5$ billion, but this is based on little more than a guess that the average amount each former player might receive in a successful suit would be $\$ 500,000$. Id. Another speculation is that costs for current players could add more than another half-billion to the total. Id.

16 See infra notes 30-32 and accompanying text.

17 See Ben McGrath, Does Football Have a Future?, New Yorker (Jan. 31, 2011), http://www.newyorker.com/reporting/2011/01/31/110131fa_fact_mcgrath.

18 This facile connection was challenged in a compelling piece by Daniel Engber. Daniel Engber, The Concussion Panic, SLATE (May 9, 2012, 6:13 PM), http://www.slate.com/ articles/health_and_science/science/2012/05/junior_seau_s_suicide_are_concussions_responsible 
both a reflection of the recent interest in this topic and an attempt to analyze possible approaches to the problem (including litigation).

This Article offers a public health perspective on the issues of concussions and related head injuries in sports. I begin with the assumption that football is unlikely to be abolished and briefly explore how the risks inherent in that sport compare to those encountered by athletes in other sports. It is important to put risks into context and not to single out any one sport (even if that sport is especially risky), to avoid missing the bigger picture. I then discuss the steps that can be taken, and some of the measures that have already been introduced, to mitigate the effects of the violence that is endemic to participation in sports-not all sports, but not just football either.

Cumulatively, these measures stand a good chance of greatly reducing the incidence of traumatic head injury and its long-term sequelae. By taking many small-scale precautions, those making rules for the safer conduct of football can achieve gains that might paradoxically be harder to achieve if the issue bogs down in a discussion of the "greater question" of whether football should be abolished. Public health advocates should be supportive of well-designed efforts to make sports safer: reducing the number of occurrences (incidence) and population burden (prevalence) of any harmful outcome is good public health practice. I conclude with a few remarks about the use and limitations of compensation in concussion-related cases.

\section{RISK OF SPORTS INJURY: FROM THE NFL TO RHYTHMIC GYMNASTICS}

Although much attention has been focused on a single kind of injury (to the brain) within a certain league (the NFL) of one sport, it is useful to step back and place this discussion in context. Virtually all sports—even non-contact sports—carry some risk of injury. Athletes playing hockey and soccer are at some risk of concussion. ${ }^{19}$ Gymnasts and divers are injured when the errors inherent in their efforts cause them to crash into their equipment. Runners' injuries include an assortment of ailments to their hips, knees, and feet. As tennis has evolved into a nuclear exchange of baseline blasts, players have been beset by injuries to their backs, wrists, shoulders, hips, and, of course,

\footnotetext{
_.html. Engber's skepticism was validated by a subsequent autopsy of Seau, but that report did not receive the same attention as the initial speculation. Tony Perry, Junior Seau Autopsy Finds No Signs of Drugs or Brain Damage, L.A. TIMES, Aug. 21, 2012, at AA3, available at http://articles.latimes.com/2012/aug/21/local/la-me-0821-junior-seau-20120821.

19 See infra notes 55-56 and accompanying text.
} 
their legs. Even swimmers, who are relatively "safe" because of the cushioning effect of the water, may suffer from shoulder tendinitis, sometimes so seriously that surgery is required.

But contact sports raise the level of concern and cause injuries to spike. The harmful results of the biophysics of collision are many, and are often painful. At their extreme, these collisions can cripple and even kill. As Daniel Engber points out, these injuries can take an enormous psychological toll, especially on former athletes whose selfdefinition is challenged by their inability to function in a pain-free, efficient way. ${ }^{20}$

The foregoing statements are summaries of obvious points, but worth making here to provide context to the concern about brain injuries. In one sense, injuries to the brain-after all, a part of the body! - are no different from the many other injuries that athletes in every sport have to deal with. But because such injuries affect us cognitively, they are a proper source of special concern. As Paul Butler said, "Our brain is really who we are. In this society, in this time, if your brain has been altered, you have been fundamentally altered." ${ }^{21}$ Thus, the recent emphasis on preventing head injuries does seem warranted, but should not provide cover for failing to address other injuries and devising ways to prevent them-or at least to mitigate their effects. No public health initiative worthy of the name neglects the interrelated injuries that result from participation across the whole range of sports.

The harms caused by repeated blows to the head have been the subject of a great deal of attention in peer-reviewed literature and the popular press, and no attempt will be made to recount them in detail here. The bottom line, though, is chilling. In September 2012, an article in the journal Neurology found that veterans of the NFL were between three and four times more likely than the general population to die from various brain diseases. ${ }^{22}$ The lead author stated that although the increased incidence of mortality was attributed to conditions including Alzheimer's disease and ALS (sometimes known as Lou Gehrig's disease), CTE was likely at least partly responsible for a number of the deaths. The role of CTE (which cannot be diagnosed until

Engber, supra note 18.

21 Brownfield, supra note 1.

22 Everett J. Lehman, et al., Neurodegenerative Causes of Death Among Retired National Football League Players, NeURology (Sept. 5, 2012), http:/www.neurology.org/content/ early/2012/09/05/WNL.0b013e31826daf50.abstract. The article also noted that the overall risk of mortality was reduced by about half, compared to the general population. $I d$. 
death) in the illness and death burden related to head trauma is not fully understood but is increasingly seen as an important contributing factor. ${ }^{23}$ Caused by repetitive brain trauma, this degenerative disease is believed to cause a range of distressing outcomes including: "memory loss, confusion, impaired judgment, impulse control problems, aggression, depression, and, eventually, progressive dementia.. ${ }^{24}$

Head injuries are likely to be most serious when two players collide. These injuries are even more serious when faster, heavier, and stronger players are involved. Indeed, the Neurology study found that "speed players" (essentially all but the linesmen) were at much greater risk for head injury than their more stationary teammates. The effect of high-speed collisions obviously does not change based on the sport; the brain does not know the difference. But there may be aspects of football, and of professional football in particular, that affect and increase the risk of injury.

First, consider the sheer size and speed of the average professional football player. Collisions between two such players are bound to create substantial trauma. Moreover, since the risk of long-term harm is increased when players return to play before the effects of previous collisions have subsided, the economics of the professional game may have made the situation worse. NFL players are known to compete with injuries that would make it difficult for many people to function even at a basic level. That "play-at-all-costs" ethos extends to brain trauma as well. The complaints against the League are quite direct in charging the NFL with falsely assuring the players that it was safe to return to play soon after suffering a concussion. For example, Woods v. NFL alleges that the League created the oxymoronically named Mild Traumatic Brain Injury Committee as a way to "mislead

23 See Press Release, American Academy of Neurology, NFL Players May be at Higher Risk of Death from Alzheimer's and ALS (Sept. 5, 2012), http://www.aan.com/press/? fuseaction $=$ release.view $\&$ release $=1101$. The study's lead author, Everett J. Lehmann, had this to say,

Although our study looked at causes of death from Alzheimer's disease and ALS as shown on death certificates, research now suggests that chronic traumatic encephalopathy (CTE) may have been the true primary or secondary factor in some of these deaths. A brain autopsy is necessary to diagnose CTE and distinguish it from Alzheimer's or ALS. While CTE is a separate diagnosis, the symptoms are often similar to those found in Alzheimer's, Parkinson's and ALS, and can occur as the result of multiple concussions. Id.

24 See What is CTE?, B.U. CENTER FOR THE TREATMENT OF CHRONIC ENCEPHALOPATHy, http://www.bu.edu/cste/about/what-is-cte/ (last visited Oct. 29, 2012). 
NFL players and. retirees" ${ }^{25}$ and that this committee "systematically and falsely mandates that "many NFL players can be safely allowed to return to play' on the same day that they sustain a concussion., ${ }^{26}$

Of course, the NFL provides its players with state-of-the-art equipment designed to cushion them against the worst effects of these impacts. Yet even this technological accomplishment turns out to be of doubtful benefit, as this level of protection may be at least partly responsible for the (d)evolution of the sport into a series of head-tohead collisions. If the helmets are meant to protect the players, the thinking may have been, why worry about such impacts? The complaints implicate the helmet manufacturer (Riddell, Inc.) in designing an unsafe product. ${ }^{27}$ Counts 50 through 52 of the Woods complaint allege that the manufacturer and the NFL represented that the helmets were safe for their intended use (which presumably, but does not clearly, include deliberate head collisions), when in fact they were not. $^{28}$

It is probably true that because of the number of people who play football and the fact that contact is essential to the sport, the risk of concussion and other traumatic brain injury is greatest in this sport. But the NFL is not the only place where football is played, and football is not the only contact sport that creates a risk of injury.

The attention to concussion and sub-concussive impacts in the NFL has begun to cascade down to lower levels of football too-and "across" to other sports. Some of these efforts seem sound and are likely to result in a decreased burden of injury on a population-wide basis.

\section{STEPS TO REDUCE THE INCIDENCE OF CONCUSSION AND THE LONG-TERM EFFECTS OF REPEATED BRAIN TRAUMA: EXPLANATION AND EVALUATION}

The NFL has itself "gotten religion" on the need to protect the long-term health of its players. As one prominent example, Commissioner Roger Goddell was recently heard at the Harvard School of Public Health discussing the need to improve safety by changing the

25 Complaint II 4, Woods v. Nat'l Football League, No. 12-10197, 2012 WL 3802438 (Fla. Cir. Ct. June 26, 2012).

26 Id. II 5.

27 Id. IIII 235-248. The NFL is also implicated in the helmets' design.

28 Id. IIT 598-615. 
culture to one in which players protect each other and inform coaches when a teammate is suffering symptoms of head injury.

One can speculate about the reason for this change of heart, and it is fair to point out that the existing lawsuits and public relations problems for the League are a greater spur to change than any underlying concern about the players. But from the public health point of view, reasons matter less than results. There is a limit to what can be done, of course. As noted above, professional football players are strong and fast. Short of changing the very nature of the sport (say, by removing the element of tackling in favor of "capturing a flag") there will always be a risk of harm to life and limb. Yet steps have been taken nonetheless. Since the 2010 season, the NFL has been cracking down on deliberate helmet-to-helmet contact. ${ }^{30}$ While this change brought outcries from some of the players themselves, ${ }^{31}$ the move has generally been lauded as a necessary step toward reducing the incidence of serious head and brain injury. As one sports analyst and former player stated, "Your helmet is put on for protection. It is not a weapon. You can clearly see when it is deliberate.,"32

Although the effect of this effort will not be known until there are long-term studies comparing the populations of former players whose careers were spent before and after this rule change, the raw physiology of the matter suggests that this easy, commonsense measure will yield improvements. There are limits, though, to how much the danger can be reduced by so-called "heads-up" tackling. According to Matt Chaney, "[s]o long as football players wear helmets, they [a]re going to bash each other with them. There [i]s no such thing as safe tackling ....."33 Perhaps, there can be safer tackling. Again, the

29 Kevin Paul Dupont, Commissioner Roger Goodell Advocates 'Culture of Change' for NFL, Boston Globe, Nov. 15, 2012, at C4, available at http:/www.boston.com/sports/ football/2012/11/15/commissioner-roger-goodell-advocates-culture-change-for-nfl/kR9RYUajQa0itRS shkiXAN/story.html.

30 See Mark Martin, Helmet Hit Injuries Prompt NFL Changes, CBN NEws, Oct. 20, 2010, http://www.cbn.com/cbnnews/healthscience/2010/October/Helmet-Hit-Injuries-Prompt-NFL-

Changes/ (describing controversy over crackdown on such hits).

31 See Steven T. Morris, NFL Enforces New Rule, WikinUT, Nov. 17, 2010, http://news.wikinut.com/Helmet-2-Helmet-contact-rule.-Changing-the-game-for-better-orworse/ovji1e $3 \mathrm{~m} /$ (quoting several players, including a member of the Chicago Bears who wryly suggested that the league change its name to the "National Flag Football League").

32 See Martin, supra note 30 (quoting ESPN analyst Merrill Hoge, whose career was cut short by concussions).

33 Matt Chaney, The Tackling Technique Roger Goodell Says Will Make Football Safer (It Won't), SLATE (Nov. 12, 2012, 4:06 PM), http://www.slate.com/articles/sports/sports_nut/ features/2012/nfl_2012/week_10/heads_up_football_the_tackling_technique_roger_goodell_says _will_make_the.html. 
goal should be a reduction in the incidence of head trauma, and perhaps an emphasis on body-to-body contact will help. The Centers for Disease Control and Prevention ("CDC") appears to think so. It has partnered with the NFL and related entities to produce a poster that discusses facts about, and symptoms of concussions, and ends with this large-type warning, "Work smart. Use your head, don't lead with it."

Yet the NFL has some distance to cover. For example, it continues to give the players discretion on which of a number of approved helmets to use, despite the existence of evidence suggesting that some brands are more successful than others at reducing the incidence of concussions.

It is particularly crucial that the NFL take steps to reduce the effects of traumatic-head injury, as it may inspire other, lower-level football leagues to follow suit. As I have written elsewhere, ${ }^{36}$ these leagues, to an extent, take their cue from the NFL, to which many of the players (and the leagues themselves) aspire. Indeed, the CDC poster mentioned above reminds NFL players that "[o]ther athletes are watching" what they do."

Indeed, there is plenty of evidence that these "other" leagues are taking bold steps to stem the tide of head injuries, sometimes even without waiting for the NFL to make the first move. Consider a few examples from the college level. The NCAA in 2012 put into place a rule that a player whose helmet comes off during a play must miss the next play unless the helmet was pulled off by an opposing player. The aim is to incentivize players to better secure their helmets. Although the change was greeted with howls of protest, ${ }^{38}$ the goal is laudable.

Moreover, the NCAA's rules for the entire sport of college football set only a floor for safety, and some leagues within the NCAA's jurisdiction have layered additional safety measures on top of those mandated. For example, the Ivy League in 2011 limited the number of full-contact practices that a team may have: while the NCAA permits

34 Partnering to Help Take Concussions Out of Play, CENTERs FOR DisEASE CONTROL AND PREVEnTION, http://www.cdc.gov/concussion/sports/nfl_poster.html (last visited Nov. 15, 2012) (displaying the Concussion poster) [hereinafter CDC].

35 See Sam Borden, Despite Risks, NFL Leaves Helmet Choices in Players' Hands, N.Y. TIMES, Sept. 20, 2012, at A1, available at http://www.nytimes.com/2012/09/21/sports/ football/despite-risks-nfl-leaves-helmet-choices-in-players-hands.html? pagewanted=all.

36 See John Culhane, The NFL's Next Big Headache, SLATE (Feb. 2, 2011, 4:27 PM), http://www.slate.com/articles/sports/sports_nut/2011/02/the_nfls_next_big_headache.html.

37 CDC, supra note 34.

38 See John O'Connor, Coaches and Players See Flaws with NCAA's New Helmet Rule, TIMES-DisPATCH (Sept. 19, 2012), http://www.timesdispatch.com/sports/coaches-and-players-seeflaws-with-ncaa-s-new-helmet/article_234c8cab-86a3-510a-bc3b-ec0f1771194c.html. 
up to five such practices per week, the Ivy League limits that number to two. ${ }^{39}$ The rule is supported by at least one study, which showed that although the number of hits to the head is greater during a game than in practice, the overall incidence of such hits was greater in practice (given the relative number of practices and games).

Helpful changes continue to seep down to lower levels of the sport, too. Sometimes these changes are driven legislatively and other times by sports leagues. By now, almost all states have in place laws designed to reduce the burden of head injuries that occur (or that are even suspected to have occurred) during interscholastic games. A newly launched site, LawAtlas, contains a very useful compendium of these laws. ${ }^{41}$ It is possible to cross-reference them, thereby revealing the states that have the most comprehensive measures. Texas, where the popularity of football is the stuff of modern mythology, ${ }^{42}$ is perhaps not surprisingly one of only two states (neighboring Louisiana is the other) that covers all of the categories marked on the LawAtlas site. The state's law went into effect in 2011 and attempts to cover a range of issues. Where a concussion is suspected, ${ }^{43}$ the player must be removed from play. ${ }^{44}$ Parental notification is then required, ${ }^{45}$ and specific steps, including written clearance by a medical professional, must be followed before the player is cleared to return to play. ${ }^{46}$ Texas also requires programming to raise awareness about the effect of head injuries (and their prevention). Coaches must be trained, ${ }^{47}$ and both parents and students must sign an approved form annually indicating their understanding of their risk of concussion.

Even more might be done. For example, as the evidence continues to build about the long-term effects of repeated subconcussive impacts, it is wise to remove a player who has suffered a blow to the

39 Ashley McDonnell, Ivy League Limits Full-Contact Football Practices, BROWN DAILY HERALD (July 31, 2011), http://www.browndailyherald.com/ivy-league-limits-full-contactfootball-practices-1.2608441.

40 See id. (citing study of three Division I football teams in Journal of Athletic Training.

41 See Hosea H. Harvey, Sports Concussion Laws Map, LAwATLAS, http://lawatlas.org/preview?dataset=sc-reboot\&id=506d89e170f72f260c000000 (last visited Nov. 2, 2012).

42 The critically acclaimed book H.G. "BuZZ” BISSINGER, FRIDAY NiGHT LiGHTS (1990), which later inspired a movie and a television show of the same name, chronicled the importance of football in one Texas town, and, by implication, across the state more broadly.

43 TEX. EDUC. CODE $\$ 38.156$ (2012).

44 Id.

45 TEX. EduC. CODE $§ 38.157$ (2012) (by implication).

46 Id.

47 TEX. EDUC. CODE $\$ 38.158$ (2012).

48 TEX. EduC. CODE $\$ 38.155$ (2012). 
head, even where a concussion is not suspected. ${ }^{49}$ Also, nothing in the law limits the number of full-contact practices per week. High schools should follow the lead of the Ivy Leagues on this score.

It will be important to gather data on the efficacy of these laws. Often, legislation enacted in response to a problem that has gathered national media attention is not as effective as its proponents hope it will be in changing the outcome that has been the focus of attention. It is doubtless true that such laws can themselves spur further dialogue, but they can also create a false sense that the problem has been solved. Again, evidence is the crucible in which such laws and policies can be tested. It might turn out, for example, that these measures would be most effective if yoked to a complementary restriction on the amount of practice time that could be spent in contact-related drills. As noted above, that measure seems likely to stanch the most serious effects of the violence by the simple expedient of reducing the number of times the players' bodies collide with each other. And as explained below, it is not only at the college level that such steps have been implemented.

The Pop Warner League has also taken steps to ameliorate the effects of the violence football demands. By far the nation's largest youth football league, Pop Warner serves about 250,000 kids nationwide in elementary and middle school. ${ }^{50}$ In 2012, the organization commanded coaches to spend at least two-thirds of practice time in non-contact drills. It has also banned some common drills completely. ${ }^{51}$ It is difficult to know whether these moves will be sufficient to reduce the burden of concussion and other head trauma, but in any case that burden needs addressing. Evidence is beginning to come in concerning the population burden of head trauma on youth. For example, a recent study published in the American Journal of Public Health revealed that a significant percentage of children younger than eighteen continued to require services one year after a mild to moder-

49 See, e.g., M.L. Dashnaw et al., An Overview of the Basic Science of Concussion and Subconcussion: Where We Are and Where We Are Going, 33 NEUROSURGICAL Focus E5:1, (2012), abstract available at http://www.ncbi.nlm.nih.gov/pubmed/23199428.

50 The most recent available numbers are from 2010, and are available on the organization's website. See Football, POP WARNER, http://popwarner.com/football/ (last visited Dec. 5, 2012).

51 See Anahad O'Connor, Trying to Reduce Head Injuries, Youth Football Limits Practices, N.Y. TIMES, June 13, 2012, at A1, available at http:/www.nytimes.com/2012/06/14/sports/popwarner-football-limits-contact-in-practices.html. 
ate head trauma that sent them to the emergency room. ${ }^{52}$ The study suggests that, even though severe head trauma is quite rare, the overall burden created by lesser trauma is actually greater, given the higher incidence of such injuries.

Of course, these moves have good collateral effects as well. By reducing the number of full-contact practices, football leagues address not only the problem of head injury, but also other injuries from this violent sport. As noted earlier, solutions that address not only the presenting problem, but related issues, commend themselves to those addressing the public health consequences of athletics.

Another beneficial effect is the spillover effect into other sports in which head injury is a risk. Indeed, the state laws collected at the LawAtlas site generally do not single out football for "special" treatment. The Texas law, again by way of example, imposes its requirements throughout the spectrum of interscholastic sports. Of particular note here is the requirement, mentioned earlier, that coaches of such sports (apparently without exception) undergo training on "the subject matter of concussions, including evaluation, prevention, symptoms, risks, and long-term effects." ${ }^{54}$ The salutary potential of this provision should be apparent. Coaches who, until now, might have had little understanding of concussions (either because they are rare in a particular sport, or because the coach simply did not "see" them), will now be furnished regular training designed to prevent concussions, and to identify them when they do occur.

In short, by addressing a problem publicized in one sport, these laws may end up reducing the overall incidence of concussions simply by drawing attention to problems in other sports that may have been long overlooked. While ice hockey has understandably been often mentioned as a sport with a high risk of head trauma, ${ }^{55}$ similar risks have gone underreported (and therefore insufficiently dealt with) in sports such as boys' and girls' soccer, and field hockey. In fact, there is some reason to think that female athletes are on average more likely

52 See Frederick P. Rivara et al., Incidence of Disability Among Children 12 Months After Traumatic Brain Injury, 102 AM. J. PUB. HEALTH 2074, 2075-76 (2012).

53 See id.

54 TEX. EDUC. CODE $\$ 38.158$ (2012).

55 See Reducing Hockey Concussion Risk, MAYO CliniC 2010 ANNUAL RePORT, http://www.mayoclinic.org/annualreport/2010/education/hockey_concussions.html. 
than their male counterparts to suffer concussions from the same impact. $^{56}$

\section{AFTER INJURY OCCURS: LITIGATION AND COMPENSATION}

As in all things public health-related, prevention is the best approach. This is true of the risk of concussions throughout sports, but when it comes to children who do not have the legal or cognitive capacity to consent to being harmed, reducing the incidence and severity of harm should remain the principal goal. But what should be done when injury occurs, as will certainly continue? Compensation will in many cases be appropriate. Before I discuss issues related to specific situations, some background in general legal principles appropriate to sports injuries will be helpful.

Typically, consent is the central legal issue in sports injury cases. Boxers cannot sue each other for the injuries inflicted in a sanctioned match because what would otherwise be acts of battery-the intent to make contact, with contact resulting-are not actionable when the parties consent to such contact. Only where the contact goes beyond the accepted rules of the game will a court allow an injured party to sue. For example, in Hackbart v. Cincinnati Bengals, Inc., an appellate court allowed the plaintiff's claim to proceed against an opposing player who had struck him in the back of the head after a play had ended. It was established that the defendant had acted in "anger," and the court held that the inherently violent nature of the sport did not provide a license for players to strike each other beyond what the game allowed. ${ }^{58}$ In many cases, the doctrine of respondeat superior will support a suit against the player's employer.

Where minors are involved, consent is supplied by their parents or legal guardians simply because children lack the legal capacity to consent. But where the student-athlete is of high school age, it is typical for the consent form to require the signatures of both the player and a parent/guardian. This requirement bespeaks careful practice by the school district (or state), because of the emerging "mature minor" doctrine, under which youths approaching adulthood have been held

\footnotetext{
56 See Alan Schwarz, Girls Are Often Neglected Victims of Concussions, N.Y.TIMES (Oct. 2, 2007), http://www.nytimes.com/2007/10/02/sports/othersports/02concussions.html? pagewanted= all\&_r=0, for a good discussion of the problem.

57601 F.2d 516 (10th Cir. 1979).

58 See id. at 521.
} 
competent to consent in certain situations. ${ }^{59}$ Thus, consent forms have been created that warn - often in boldface, almost-panicky languagethat all sports are risky, and can lead to "concussion, and even death."

The state-wide consent form used for high school athletes in Florida supplies an instructive example. It covers all interscholastic sports, mentions "concussions" twice, and, after detailing the risks several times, concludes with a large-type fire alarm: "YOU ARE AGREEING TO LET YOUR MINOR CHILD ENGAGE IN A POTENTIALLY DANGEROUS ACTIVITY . . THERE IS A CHANCE YOUR CHILD MAY BE SERIOUSLY INJURED OR KILLED . . BECAUSE THERE ARE CERTAIN DANGERS INHERENT IN THE ACTIVITY WHICH CANNOT BE AVOIDED OR ELIMINATED.," ${ }^{60}$ If one did not understand the legal and sports culture of the United States, one might be surprised that any parent would allow their child to compete in some of the more dangerous sports-perhaps especially football-after reading such language.

Of course, professional sports (including but not limited to football) carry serious risks that the players know of, and consent to, usually by signing elaborate forms that acknowledge these risks and relieve the relevant league from liability when these risks result in injury.

For the most part, though, the claims against the NFL and other football leagues are not grounded in battery, but in negligence and misrepresentation (both intentional and negligent). To summarize a long and complex array of claims: the former NFL players allege that the NFL knew (intentional misrepresentation) or should have known (negligence) of the long-term risk of repeated head trauma, including but not limited to concussions, but failed to disclose those risks-and in fact covered them up. Just as consent is a defense to battery, so is assumption of risk a defense to a negligence claim, ${ }^{61}$ but it will not ap-

59 Although this doctrine is principally applied in the context of medical decision-making, see, e.g., Rhonda Gay Hartman, Coming of Age: Devising Legislation for Adolescent Medical Decision-Making, 28 AM. J. L. \& MED. 409 (2002), it is probably good practice for high schools to anticipate an expansion of law into other areas and to craft agreements that recognize this possibility.

60 Consent and Release From Liability Certificate, Florida High ScHOOL ATHLETIC Ass'N, http://www.fhsaa.org/sites/default/files/el03_consent_5.pdf (last visited Nov. 16,2012).

61 The trend in assumption of risk cases is to atomize the issues into three discrete categories. Express assumption of risk is anchored in a contractual agreement between the parties whereby the plaintiff agrees to hold the defendant harmless for injury. See DAN B. DobBS, THE LAW OF TORTS $\S 213$ (2000). There are also two forms of implied assumption of risk. Primary assumption of risk is appropriate for cases in which the facts support a conclusion that the de- 
ply unless the plaintiff voluntarily encountered a known risk. So the defense will be unavailing if the former players can establish the league's superior knowledge, or even the NFL's access to relevant information. As for misrepresentation, the intent to deceive, coupled with the players' reasonable reliance on the league's assurances, will be the crucial issues. To a neutral observer, these claims look promising, but, as I have written elsewhere, ${ }^{62}$ the outcome will likely turn on what the league knew, and when. And even if culpable conduct can be established, numerous other obstacles could bedevil efforts to recover compensation, including the primacy of workers' compensation law, the possible preemptive effect of the collective bargaining agreement between the players' union and the NFL, and the need to prove-in every case-that a given player's injury resulted from something that happened on a football field.

Claims by high school and younger players might face a tougher road, if only because it could be more difficult to establish that the relevant state and local authorities knew or should have known about the long-term effects of sports trauma. But if they did, the release quoted earlier will not save them from liability. Sovereign immunity might provide an escape in some cases, but it is on the wane across the United States. ${ }^{64}$

Litigation might in the long run prove successful, but it is probably not the best approach in these cases. It would be far better for the relevant leagues to set up a compensation fund to cover the long-term, and often uncertain, physical and psychological effects of concussions and other head trauma, and to pay for the cost of medical monitoring. The league already has a couple of compensation programs in place, including a neurological care program that provides "NFL alumni" with access to specialists at five leading medical centers. ${ }^{65}$ There is also the "88 Plan," which, as its name suggests, pays up to $\$ 88,000$ annually

fendant either did not owe the plaintiff a duty or did not breach the duty owed. Secondary assumption of risk applies where the defendant did breach a duty of reasonable care, but the plaintiff's recovery is either reduced or barred by his or her own negligence in encountering a known risk associated with the activity. See, e.g., Meistrich v. Casino Arena Attractions, Inc., 155 A.2d 90, 93 (N.J. 1959).

62 Culhane, supra note 36.

63 Id.

64 See DoBBS, supra note 61 at $\$ \$ 260$ (generally), 268 (state immunities), 269 (local immunities).

65 For an announcement and brief summary of the plan, see Alumni Association Establish New Neurological Care Program, NFL, (Mar. 24 2010, 6:36 PM), http://www.nfl. com/news/story/09000d5d8171ffab/article/nfl-alumni-association-establish-new-neurologicalcare-program. 
for the institutional care of former players suffering from dementia who have "vested" under the NFL's retirement plan."

To these, the NFL should add a deep compensation fund for those suffering from injuries and conditions that have been sufficiently linked to concussions and sub-concussions. These might include early-onset Alzheimer's, ALS, and CTE, a condition that has been found in the brains of several players whose lives have come to a tragic end (sometimes through suicide).

Such a fund would be a better remedy than tort law. By establishing certain covered conditions, the fund would eliminate questions of individual causation in most cases. A model for this approach already exists: The National Vaccine Injury Compensation Program pays hefty compensation to those who suffer serious but rare consequences from being immunized against childhood diseases. ${ }^{67}$ The vaccine program relies on a table of injuries that have been linked to given immunizations; if the alleged injury is on the appropriate table, causation is presumed. ${ }^{68}$ (Otherwise, the claimant must prove causation-no easy matter). ${ }^{69}$ A similar approach would work well in professional football. As the science progresses, more covered conditions could be added to the list, or some might be removed.

Compensation funds work well when the class of victims is clear, and a dedicated funding source exists or can be established. The NFL is a good example of a situation where compensation funds would work well, as the circuit between players, injuries, and culpable parties can be nicely closed. But as we move from professional football to other sports, and especially to youth sports, it becomes more difficult to create or cabin such a fund. The class of plaintiffs becomes unclear and unmanageable, the possible defendants too diffuse, and the provenance of injury too uncertain for the fund model to operate efficiently.

If the foregoing observations accurately describe the legal landscape, their implications should be disturbing: former NFL players stand to gain compensation, but other athletes suffering concussions do not. Given that many of these victims are children with little ability to protect themselves, something else needs to be done. Perhaps

66 For a description of the plan, see 88 Plan Overview, NFL Player CARE, https://www.nflplayercare.com/88PlanOverview.aspx (last visited Dec. 5, 2012).

6742 U.S.C. $\$ \$ 300 a a-1$ to $300 a a-25$ (2013). For a fuller discussion and critique of this program, see John G. Culhane, Tort, Compensation, and Two Kinds of Justice, 55 RUTGERS L. REV. 1027, 1095-1102 (2003).

6842 U.S.C. $\$ 300 a a-11(c)(1)$ (C) (i) (2013).

6942 U.S.C. $\$ 300 a a-11$ (c) (1) (C) (ii) (2013). 
that something will be a blanket prohibition on at least the youngest kids playing tackle football, but that outcome does not seem in reasonable prospect in the near future. Thus, the best we can probably do is what public health does best when it is working well: create, and then evidence-test, a variety of prevention initiatives that combine to reduce the incidence and severity of injury, especially trauma to the developing brain. The inability to solve a problem completely should not dissuade us from doing something. The steps already taken should be built on, and quickly. 